\title{
Cross-Talk Signaling in Rice During Combined Drought and Bacterial Blight Stress
}

\section{Ramu S. Vemanna ${ }^{1,2 *}$, Rahul Bakade ${ }^{3}$, Pooja Bharti', M. K. Prasanna Kumar ${ }^{3}$, Sheshshayee M. Sreeman', Muthappa Senthil-Kumar ${ }^{4}$ and Udayakumar Makarla1}

\begin{abstract}
${ }^{1}$ Department of Crop Physiology, University of Agriculture Sciences, Bengaluru, India, ${ }^{2}$ Regional Center for Biotechnology, Faridabad, India, ${ }^{3}$ Department of Plant Pathology, University of Agriculture Sciences, Bengaluru, India, ${ }^{4}$ National Institute of Plant Genome Research, New Delhi, India
\end{abstract}

\section{OPEN ACCESS}

Edited by:

Sonia Negrao,

University College Dublin, Ireland

Reviewed by:

Robert Henry,

The University of Queensland,

Australia

Kazuo Nakashima, Japan International Research Center

for Agricultural Sciences, Japan Wusirika Ramakrishna

Central University of Punjab, India

${ }^{*}$ Correspondence:

Ramu S. Vemanna ramu.tiger123@gmail.com; ramu.vemanna@rcb.res.in

Specialty section: This article was submitted to

Plant Abiotic Stress,

a section of the journal

Frontiers in Plant Science

Received: 03 January 2018 Accepted: 05 February 2019

Published: 06 March 2019

Citation:

Vemanna RS, Bakade R, Bharti P, Kumar MKP, Sreeman SM,

Senthil-Kumar M and Makarla U (2019) Cross-Talk Signaling in Rice During Combined Drought and Bacterial Blight Stress.

Front. Plant Sci. 10:193.

doi: 10.3389/fpls.2019.00193
Due to climatic changes, rice crop is affected by moisture deficit stress and pathogens. Tissue water limitation besides reducing growth rates, also renders the crop susceptible to the infection by Xanthomonas oryzae pv. oryzae (Xoo) that causes bacterial leaf blight. Independently, both drought adaptation and Xoo resistance have been extensively studied. Though the cross-talk between drought and Xoo stress responses have been explored from individual stress studies, examining the combinatorial stress response is limited in rice. Recently published combined stress studies showed that under the combined stress, maintenance of carbon assimilation is hindered and such response is regulated by overlapping cellular mechanisms that are different from either of the individual stresses. Several receptors, MAP kinases, transcription factors, and ribosomal proteins, are predicted for playing a role in cellular homeostasis and protects cells from combined stress effects. Here we provide a critical analysis of these aspects using information from the recently published combined stress literature. This review is useful for researchers to comprehend combinatorial stress response of rice plants to drought and $X_{O O}$.

Keywords: combined stress, rice, Xanthomonas, drought, QTL, protein synthesis

\section{INTRODUCTION}

Plants are simultaneously exposed to diverse biotic and abiotic stresses that result in reduced yields in many crops (Atkinson et al., 2013; Narsai et al., 2013; Prasch and Sonnewald, 2013; Suzuki et al., 2014; Pandey et al., 2015b; Ramegowda and Senthil-kumar, 2015; Bahuguna et al., 2018). Rice is generally grown under puddled conditions, however, due to shortage of water availability, water saving technologies have been adapted for crop production (Lampayan et al., 2004). The unexpected drought has a significant impact on nearly 23 million hectares of rain-fed rice growing area in Southeast Asia. During these situations, many bacterial pathogens infect plants and further reduce the yield. A combined effect of bacterial blight (BB) caused by Xanthomonas oryzae pv. oryzae (Xoo) and drought situations in dry season cause significant yield losses in South Asia and 
South Africa (Ogawa, 1993; Verdier et al., 2012; Dixit et al., 2014). However, highest yield losses were reported in drought stress followed by temperature, weeds, and diseases (Pantuwan et al., 2000; Savary et al., 2012; Singh et al., 2012; Aghamolki et al., 2014; Ghadirnezhad and Fallah, 2014).

Water limitation with its effect on tissue water relations besides reducing growth rates also renders the crop susceptible to the infection by Xanthomonas. Both drought adaptation and Xoo resistance have been extensively studied with significant leads. Understanding the response of the crop to a combination of drought and $\mathrm{BB}$ is a relevant topic. The major premise emerged from the fact that some mechanisms leading to stress adaptation could have a common link through protecting plant metabolic efficiency under these stresses (Ramegowda and Senthil-kumar, 2015).

The combined simultaneous occurrences of abiotic and biotic stresses depend on the host resistance or susceptibility and also on the race of pathogens (Tippmann et al., 2006). The multiple stress occurrence and microclimate of plantmicrobe interactions also influence the response of the host plant. Overlapping plant responses to drought and bacterial stress have been reported in Arabidopsis, rice, chickpea, and sunflower (Atkinson et al., 2013; Prasch and Sonnewald, 2013; Choudhary et al., 2016; Vemanna et al., 2016). There are several common changes in morphological, physiological traits and biochemical responses of plants to drought and pathogen stresses (Pandey et al., 2017). Leaf wilting, decrease in tiller number and biomass are common processes affected in both drought and bacterial infections in rice. However, increased root growth and reduced leaf expansion, stem elongation and leaf number are observed only under drought and localized lesions, patchy brown spots or pale yellow leaves were observed upon bacterial infection in rice. There are common and unique plant responses observed in response to both stresses when exposed independently. These symptoms could be common, which may serve as morphological observations to identify the combined stress response in rice. $\mathrm{ABA}$ and ethylene increases in plants with concomitant reduction of photosynthetic ability under combined stresses (Grimmer et al., 2012; Zhang and Sonnewald, 2017). In these conditions, antioxidant enzymes are accumulated to scavenge the ROS generated under stress. However, ROS accumulation under pathogen infection is the cause for a hypersensitive response suggesting that ROS play similar and opposite complex functions in plant adaptation under combined stresses. Sugars and polyamines are also accumulated for stress protection under combined stresses. All these mechanisms have relevance in imparting combined stress tolerance.

The stress tolerance mechanisms adapted by rice under combined stresses is diverse that include some common/shared and unique responses. The common visible effects include wilting, reduction in tiller number due to the blockage in xylem that reduces the water flow, which affects photosynthetic machinery (Fatima and Senthil-Kumar, 2017). Droughtinduced low tissue water potential and lesions caused by bacterial infection further decreases the photosynthesis and reduce yield.

\section{TRANSCRIPTIONAL RESPONSES TO INDIVIDUAL AND COMBINED STRESS OVERLAP}

A comprehensive understanding of crosstalk or regulatory networks involved in unique or shared responses for either individual or multiple stresses is much-needed (Pandey et al., 2015a). A deluge in omics data has provided greater insight into the diverse aspects of spatiotemporal responses of stresses in plants. Only a limited amount of data is available in public domain for combined stresses, especially, for drought and Xanthomonas infection. The meta-analysis studies using transcriptome data from different plant species have identified shared genes which acts simultaneously or independently under different stress conditions (Shaik and Ramakrishna, 2013, 2014; Vemanna et al., 2016). Meta-analysis of eight different viruses infecting Arabidopsis revealed several regulatory genes which are competently connected to the plant defense response (Rodrigo et al., 2012). These meta-analysis data help in understanding the crosstalk of specific genes between stress conditions.

Rice plants have evolved common molecular responses, which exhibit cross-talk between different hormones such as ABA, ethylene, salicylic acid, jasmonic acid, cytokinin, and brassinosteroid. The data from a few transcriptome analysis indicates the existence of crosstalk mechanisms between signaling networks under drought and pathogen stress (Figure 1) (Schenk et al., 2000; Cheong et al., 2002; Seki et al., 2002). Hormones play a crucial role as central regulators of many downstream responsive transcription factors (TFs) and functional proteins. The receptors for abscisic acid (ABA), brassinosteroids (BRs) and many pathogens triggered elicitors have been identified. Some are PYR1/PYL/RCAR, BAK1, and LRR kinases which act as $R$ genes for many pathogens and also acts as key receptors in abiotic stress signaling (Figure 1). The signals received by these elicitors activates or phosphorylate the downstream protein kinases cascade to activate several TFs. The members of WRKY, NAC, AP2/ERF, bZIP, and MYC family TFs showed altered responses to both biotic and abiotic stresses (Babitha et al., 2013, 2015a,b; Xiao et al., 2013; Zhang et al., 2016; $\mathrm{Ku}$ et al., 2018) and played a major role in combined stresses. The reactive oxygen species (ROS) generated under oxidative stress showed unique responses to bacterial and drought stresses that trigger downstream stress responses (Apel and Hirt, 2004; Narusaka et al., 2004; Torres and Dangl, 2005). The calcium signaling is considered as a central hub in concurrent biotic and abiotic stress responses (Ranty et al., 2016; Ku et al., 2018). The signals of $\mathrm{Ca}^{2+}$, inositol-3-phosphate and protein kinases and other kinases also have a significant role in combined stresses. Thus crosstalk between biotic and abiotic stress signaling pathways regulate many cellular processes.

The individual transcriptome data from biotic and abiotic stress have identified antagonistic and overlapping responses (Narsai et al., 2013). The computational comparison of the 


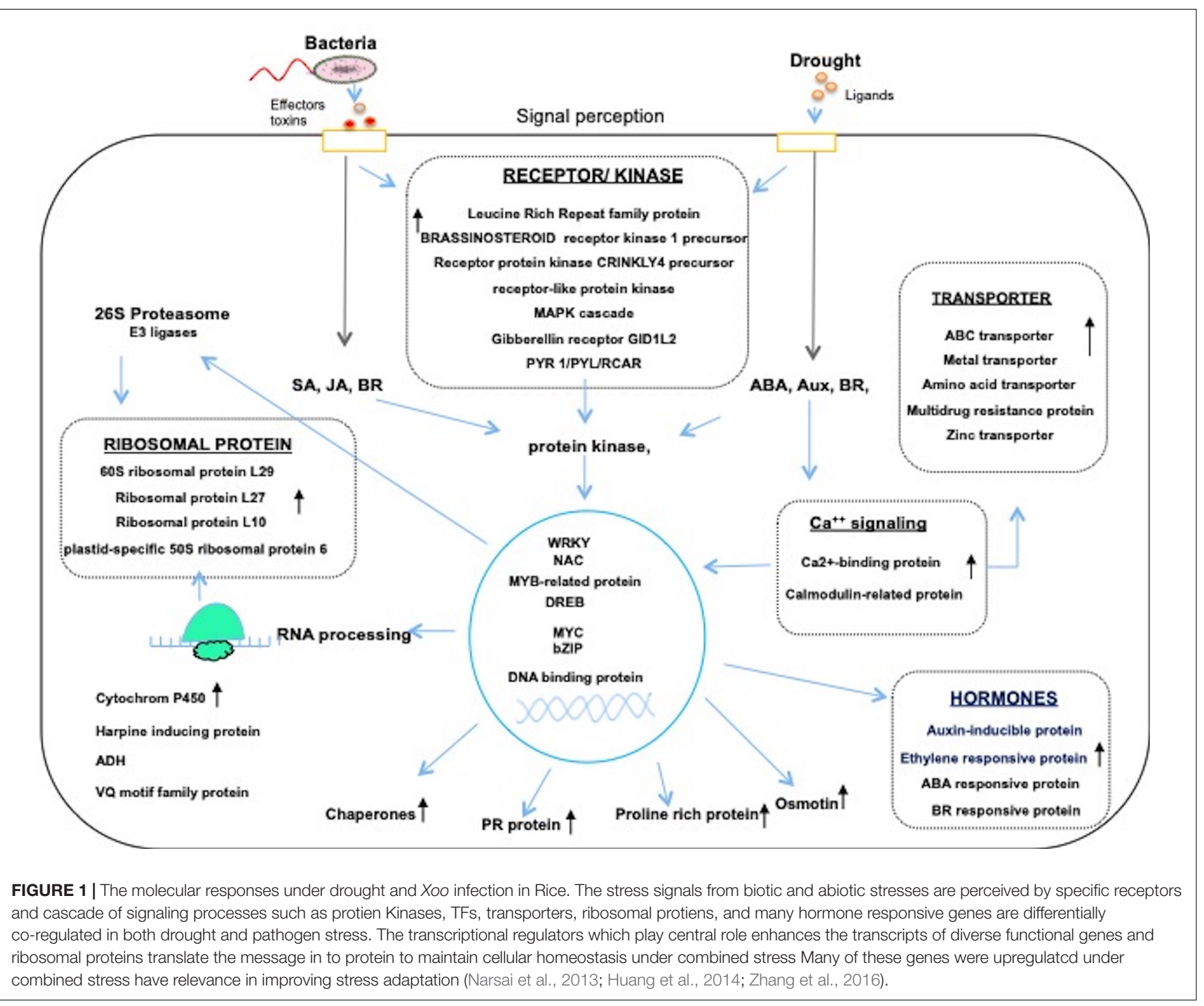

expression profile between abiotic and biotic stresses has revealed unique genes that showed similar response across multiple stresses (Jain et al., 2007; Ribot et al., 2008; Swarbrick et al., 2008; Hu et al., 2009; Marcel et al., 2010; Zhou et al., 2010; Narsai et al., 2013). The studies suggest that the plants respond to combined multiple stresses by crosstalk of several hormonal signaling pathways (Sharma et al., 2013; Bahuguna et al., 2018; Ku et al., 2018). In response to drought and Xoo infection, 2276 genes showed overlapping differential expression profiles (Narsai et al., 2013). In another, metaanalysis study between drought and bacterial stress in rice 5084 DEGs have been identified by combining the data sets. Among 1214 common genes, 565 genes were upregulated and 309 downregulated in both drought and bacterial stresses (Shaik and Ramakrishna, 2013). In a comparative study of drought and $\mathrm{Xoo}$, transcriptome analysis of the resistant rice introgressed line $\mathrm{H} 471$ when compared with the recurrent parent HHZ and 306 and 840 DEGs were identified and amongst them 178 genes were common for both stresses (Zhang et al., 2016).

In combined drought and Xoo infection, many components of the multiple pathways responded similarly. Several genes showed opposite roles in response to pathogens and abiotic stress tolerance (Xiong and Yang, 2003; Asano et al., 2012). The OsCPK12 acts as a negative regulator for blast resistance but positively regulates salt, drought, and cold stress tolerance in rice (Asano et al., 2012). The broad-spectrum disease resistance through $P R$ genes is negatively regulated by OsMAPK5 (Xiong and Yang, 2003). In resistant introgressed lines H471, two genes (LOC_Os04g56000 and LOC_Os12g43410), were strikingly up and down-regulated in combined drought and Xoo infection. The studies suggest that the drought tolerance and $\mathrm{BB}$ resistance mechanisms are shared in resistance genotypes. Further, phosphate/phosphorus metabolic process, phosphotransferase activity, and kinase activity associated genes and peptidase/endopeptidase/enzyme inhibitor activity genes 
were highly represented in up-regulated genes. The TFs WRKY and NAC showed a conserved response between abiotic and biotic stress (Seki et al., 2002; Narsai et al., 2013). Under both stress conditions, 10 DEGs encoding receptor kinases LOC_Os08g07760 (OsBAK1), protein kinases LOC_Os11g31530 (brassinosteroid signaling pathway) were strongly up-regulated and LOC_Os03g46910 (pyruvate kinase) was down-regulated in $\mathrm{H} 471$ introgression line which is resistant to Xoo and drought as compared with Huang-Hua-Zhan (HHZ) (Zhang et al., 2016).

In rice, the introgressed line $\mathrm{H} 471$, three DEGs involved in phytohormone signaling pathways, the BR pathway (OsBAK1) and gibberellin (GA) pathway genes were upregulated in both drought and Xoo stress. The GA20 oxidase an essential gene involved in GA biosynthesis that catalyzes the conversion of GA53 to GA20 was downregulated (Zhang et al., 2016). The GA response related to plant height was evident, and the response could be associated with GA20 oxidase expression levels (Dossa et al., 2016) The antagonistic reaction from GA with JA has been reported that they are involved in development and immunity of plants through DELLA proteins (Yang et al., 2013).

The stress-responsive signaling genes are differentially regulated in response to combined stresses. The ABC transporters such as multidrug resistance function encoding proteins, universal stress protein (LOC_Os5g28740), Q-rich domain-containing protein (LOC_Os06g04240) and lineagespecific genes (LOC_Os12g32610) were highly expressed in both stresses in rice signifying the importance of these transporters in combined stresses. In Xoo resistant genotypes, cell wallassociated genes were downregulated in $24 \mathrm{~h}$ of infection and significantly upregulated in $96 \mathrm{~h}$. The phenylpropanoid metabolism genes UDP glucosyl/glucoronyl transferases, two genes encoding cytochrome $45072 \mathrm{~A} 1$ were significantly upregulated in $X o o$ resistant type. There are receptor kinases such as OsWAK (OsWAK127), a lectin-like receptor kinase, a phytosulfokine receptor precursor and a serine/ threonine kinase-like protein, an NBS-LRR type putative disease resistance protein (LOC_Os02g30150) and resistance protein LR10 (LOC_Os04g11780) were up-regulated in response to Xoo infection, several of kinases were down-regulated in drought stress suggesting that there are specific receptor kinases exclusively responsive to individual stresses suggesting the unique signaling pathways may operate for stress adaptation by regulating downstream TFs.

The functional roles of some TFs have been elucidated in response to bacterial infection and drought stress. The TFs such as WRKY28, MYB4, AP2/EREBP-DREB, and HSF4 were differentially regulated that control several functional genes involved in multiple stresses. The $\mathrm{C} 3 \mathrm{H} 12$ zinc finger $\mathrm{TF}$ in downregulated at $96 \mathrm{~h}$ in response to bacterial Xoo infection (Narsai et al., 2013) and knock-out lines showed partially increased susceptibility in Zhonghu 11 genotype (Deng et al., 2012). Three WRKY TFs were up-regulated and had been shown to result in altered resistance. Overexpression of WRKY71 resulted in enhanced resistance to Xoo bacterial infection (Liu et al., 2007). In contrast, over-expression of WRKY45 showed increased susceptibility to Xoo (Tao et al., 2009). The NAC TFs that were upregulated in both abiotic and biotic stress also had a developmental role in plants (Hu et al., 2006; Mao et al., 2007; Tao et al., 2009; Jeong et al., 2010; Takasaki et al., 2010). Some NAC TFs were induced in response to Xoo infection and drought stress, amongst them NAC10 showed 53-fold induction in drought stress (Jain et al., 2007) and overexpression resulted in root enlargement and improved drought stress tolerance (Jeong et al., 2010). The $b H L H$ (LOC_Os01g72370), B3 (LOC_Os03g42280), and M-type (LOC_Os04g31804) TFs were up-regulated and COlike (LOC_Os09g06464) TF was down-regulated under drought and $\mathrm{Xoo}$ infections in resistant $\mathrm{H} 471$ rice genotype (Zhang et al., 2016). The VQ genes (VQ -FxxxVQxLTG motif) were shown to interact with WRKY TFs and were induced upon Xoo infection, ABA and drought stress conditions (Kim et al., 2013). The differential expression of TFs may regulate diverse functional genes, which have specific mechanisms under both stress conditions.

The cytochrome P450 monooxygenase family CYP71P1 encoding tryptamine 5-hydroxylase function involved in cell wall biosynthesis was highly upregulated in response to Xoo infection as well as fungus Magnaporthe oryzae causing Sekiguchi lesion (SL) (Fujiwara et al., 2010; Delteil et al., 2012). The SPL7 and $\mathrm{BiP} 3$ chaperons were up-regulated in resistant genotypes in response to $X o o$ infection and drought. Suppression of SPL7 resulted in increased resistance to infection (Yamanouchi et al., 2002) and Xa21 mediated immunity to Xoo infection was compromised due to overexpression of BiP3 (Park et al., 2010). Binding proteins (BiP) play chaperone functions in endoplasmic reticulum-mediated unfolded protein response, improves cellular tolerance mechanisms by maintaining the protein quality control. The genes encoding cell cycle isomerases were differentially expressed (Yao et al., 2001) in the resistant genotype when infected with bacteria and among them, eight of them were highly upregulated in response to bacteria (Narsai et al., 2013). The pathogenesis-related PR10 was induced in roots upon drought, salt stress, JA and blast fungus (Hashimoto et al., 2004).

The genes involved in protein degradation showed differential expression in combined stresses. The ubiquitin E3 complex and subtilizes were down-regulated in the resistant genotype in response to bacterial infection and drought. The speckletype POZ protein (LOC_Os10g29220.1) a subunit of E3 ubiquitin complex and a subtilisin-like protease precursor (LOC_Os04g02970.1), deaminase (LOC_Os07g46630.1) involved in nucleotide degradation were downregulated in a bacterial infection in the drought-resistant cultivar. These E3 ligases are components of the $26 \mathrm{~S}$ proteasome system are targeted by bacterial effector proteins and modulate their mechanisms against host defenses. The reduced expression of these genes in drought-resistant genotypes could be an adaptive strategy that plants have evolved to fight against Xoo infection.

\section{REGULATORY NETWORKS UNDER COMBINED STRESS}

Considerable crosstalk signaling mechanisms exist in response to combined bacterial and drought stress (Figure 2). In 


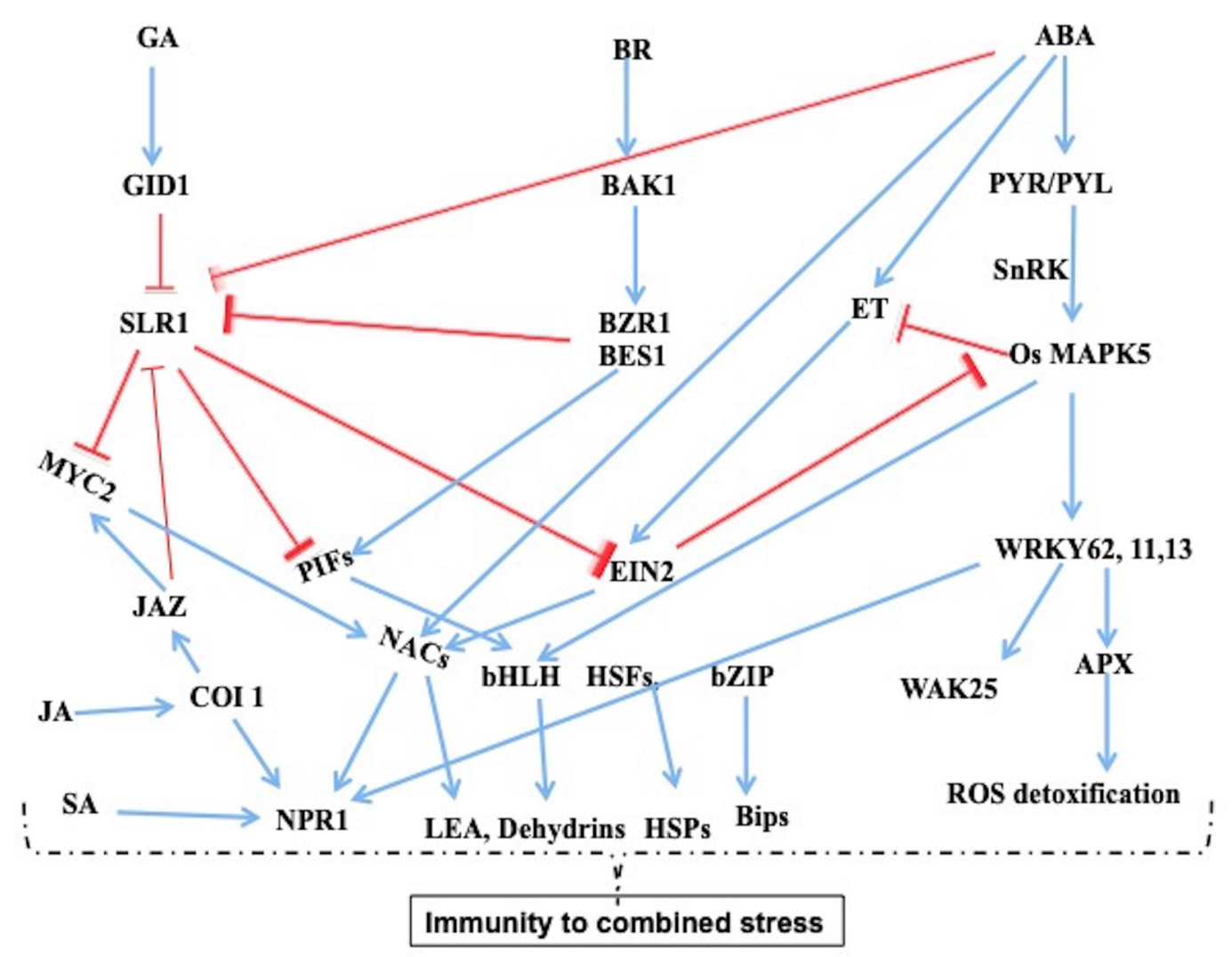

FIGURE 2 | Regulatory networks under combined stress of drought and Xoo infection in nee. The data taken from the combined stress transcriptomic studies and a model arrived from the knowledge from diverse studies. The phytohormones play crucial role in crosstalk signaling mechanisms. Some of the key genes play antogonistic, overlapping, and opposite role with response to combined stress which depends on intensity of stress and cellular homeostasis with regards protein turnover or stability. The LEAs. dchydrins, HSPs, Bips provide stability to proteins (Narsai et al., 2013; Sharma et al., 2013).

comparison with resistant rice introgressed line $\mathrm{H} 471$ and its recurrent parent HHZ, 178 common DEGs exists, among which 39 genes were found to be co-regulated in a complex network. Majority of proteins enriched belonged to stress signal perception and transduction such as $R L K, L R R$, receptor kinases, protein kinases, and the proteins were related to $B R$ (OsBAK1) and GA (GID1L2) pathways (Zhang et al., 2016). There is convincing evidence to show that certain $R L K s$ and $L R R s$ are predicted to be involved in BR signaling process, which suggests that brassinosteroids act as a central regulatory hormone in crosstalk mechanisms with other hormone signaling process under combined studies. Several protein kinases involved in phosphorylation have been identified in both $\mathrm{BB}$ and drought tolerance, which further activates the TFs. However, several genes showed opposite roles in response to different stresses in rice (Xiong and Yang, 2003; Tao et al., 2009; Asano et al., 2012). The MitogenActivated Protein Kinase 5 (OsMPK5), wall-associated kinase 25 (WAK25), WAK-like (WAKL), sucrose non-fermenting-1related protein kinase-1 (SnRK1) and SUB1A binding protein 23 (SAB23) are involved in cross-talk signaling in both abiotic and biotic interactions ( $\mathrm{He}$ et al., 1998; Kohorn and Kohorn, 2012; Sharma et al., 2013). Suppression of
OsMPK5 reduced the ABA sensitivity and increased ethylene levels, PR protein expression, hence resulted in resistance to fungus $M$. oryzae, which causes rice blast disease (Xiong and Yang, 2003; Bailey et al., 2009). SnRK1 has been identified as a central hub for signal integration for many pathways in the cross-talk mechanisms (Seo et al., 2011; Cho et al., 2012).

Downstream to these kinases several TFs are found to be commonly upregulated in both bacterial and drought stress which include HLH-type TF identified from combined stress (Zhang et al., 2016). Several TFs like NAC, WRKY, MYB, $M Y C, b Z I P, H S F$, and CO identified were known to be upregulated in both stresses and induce immune responsive genes. Overexpression of OsWRKY13 regulated SA-dependent immunity and several other physiological pathways including JA response. The SNAC1 TF involved in abiotic stress response showed improved tolerance in rice (Qiu et al., 2007). Similarly other WRKY family TFs OsWRKY45-1, OsWRKY62, 71, and 76 have an interface of the biotic and abiotic stress interactomes (Qiu and Yu, 2009; Seo et al., 2011). A few ribosomal proteinencoding genes, which include metal ion transport-related genes, PR protein osmotin, and GA associated genes, were co-regulated in resistant rice H471 type (Zhang et al., 2016). 
Several genes involved in photosynthesis, dehydrins and late embryogenesis abundant (LEA) proteins involved in protein stability that are implicated in desiccation tolerance are also co-regulated in bacterial stress (Hand et al., 2011; Shaik and Ramakrishna, 2013). ABA contributes to adaptation to osmotic stress and also involved in defense response by regulating plant physiological process which acts as a barrier for pathogen entry (Asselbergh et al., 2008; Ton et al., 2009; Kaundal et al., 2017). The BAK1 and DELLA proteins appears to be central regulators in abiotic and biotic stresses that positively affects ROS detoxification by activating many antioxidant proteins (Achard et al., 2008; Divi et al., 2010; Albrecht et al., 2012; Belkhadir et al., 2012; Sharma et al., 2013). In Arabidopsis, it was shown that the $\mathrm{BR}$ receptor $B A K 1$ is a primary signaling receptor that modulates the interaction of GA, BR, JA, and SA signaling pathways (Figure 2) (Yamada et al., 2015; Li et al., 2016; Nolan et al., 2017). DELLAs also sensitize JA signaling at the expense of SA mediated defense and enhances resistance to necrotrophic pathogens (Navarro et al., 2008). These studies demonstrate that the complex overlapping co-regulatory network of many pathways and genes contribute for adaptation to the combined stress conditions (Figure 2).

\section{RIBOSOMAL PROTEIN-ENCODING GENES ARE DIFFERENTIALLY REGULATED UNDER COMBINED STRESS}

Many omics reports over-representing genes associated with translational mechanisms such as TFs, RNA processing, RNA binding, ribosomal proteins, protein synthesis, and folding were differentially expressed. Recent studies show that the ribosomal protein-encoding genes have extra-ribosomal functions and they are involved in specific mechanisms (Nagaraj et al., 2016). Ribosomal proteins are critical for the translation of diverse proteins and involved in the overall fitness of the cell under stress conditions. From this context response of genes encoding ribosomal proteins were specifically looked in the combined stress conditions. However, the functional relevance of many of these genes with response to either individual or combined stresses is still needed. In response to bacterial infection, 50 genes encoding ribosomal proteins were up-regulated in the resistant rice genotype, and 46 of them were also up-regulated under fungal infection ( $M$. grisea). However, in drought stress, 46 ribosomal proteins were downregulated (Narsai et al., 2013). The differential responses of all the ribosomal proteins including small and large subunit encoding proteins have been studied using genome-wide studies in rice with response to multiple stress condition (Moin et al., 2016; Saha et al., 2017). The ribosomal large subunit protein encoding genes were differentially expressed in response to abiotic stresses, and amongst them, 34 genes showed significant changes. Out of which, 6 of them were RPL12, 28, 30, 36, 44, and
51 that showed down-regulation in response to Xoo. RPL38 was unchanged, and the remaining genes like RPL10, 11, 15, 24a 26, 27, 37 were activated more than 10-fold (Moin et al., 2016). The qRT-PCR analysis of small subunit encoding ribosomal protein genes revealed 14 genes downregulated, and others were upregulated in response to biotic and abiotic stresses. The RPS6a, RPS9, RPS10a, and RPS4 showed high upregulation in both biotic and abiotic stresses (Saha et al., 2017). It was observed that out of 50, 32 ribosomal protein promoters have TELOBOX elements (Narsai et al., 2013). The differential regulation of these genes suggests that, unlike there role in protein synthesis, they also possess extraribosomal functions. The precise function of each ribosomal proteins with response to combined or individual stresses need to be identified.

\section{INTROGRESSION OF QTLS FOR DROUGHT AND Xa GENES IMPROVES COMBINED STRESS TOLERANCE}

Considerable progress has been made in identifying QTLs for drought tolerance (Prince et al., 2015). Similarly, around fifty genes /QTLs for resistance against Xanthomonas bacteria have been identified in rice (Dossa et al., 2016). Most of the genes are targeted to $\mathrm{Xoo}$ that causes $\mathrm{BB}$ and are referred to as $\mathrm{Xa}$ genes (Khan et al., 2014; Zhang et al., 2014). The Xa21 being a major gene conferred resistance against bacterial infections, and subsequently, introgression of different $\mathrm{Xa}$ genes (Xa5, Xa13, and Xa21) provided broadspectrum resistance in different rice cultivars (Pradhan et al., 2015). Drought stress influences plant response to pathogens through a gene for gene interaction and depends on the severity of stress. The combined interactive effect of bacterial disease and drought QTLs are dependent on QTLs or genes associated with specific traits. However, the combined stress response depends on soil water content and genotypes having different $\mathrm{Xa}$ genes (Wright and Beattie, 2004; Dossa et al., 2016). To date, no QTLs have been identified for combined bacterial and drought stress tolerance in rice. A few studies have shown genotype dependent $\mathrm{BB}$ pathogen infection in rice plants under drought-induced conditions (Dossa et al., 2016). Though many genotypes have different $\mathrm{Xa}$ genes, increased lesions were visible under mild drought stress conditions, indicating under combined stress, rice plants are affected and bacterial virulence enhanced.

The combined stress effect at vegetative stage showed different lesion length upon BB infection under drought stress which depends on genotypes having different $\mathrm{Xa}$ genes. The genotype containing single Xa4 gene and drought QTL DTY2.2 did not show any significant BB induced lesion in either control or at severe drought conditions (Dossa et al., 2016). The susceptible IR24, IR64, and other two $\mathrm{X} a$ gene introgressed lines had reduced lesion lengths under moderate drought stress. The multiplication and spread of $X \circ o$ were increased in rice genotypes under mild drought 
stress even though $\mathrm{Xa} 4$ gene was expressed. However, under both compatible and incompatible interactions, BB disease infection was reduced under drought stress when drought severity was increased. The lesions in the single Xa4 gene containing genotypes were larger than the genotypes having $X a 7$ gene when inoculated with virulent PXO145 (avrXa4 + avrXa5 + avrXa7) indicating that the genotypes with suitable $\mathrm{Xa}$ gene may still provide resistance against the pathogen under drought stress conditions. Rice genotypes having different $X a 7, X a 4+X a 7, X a 4+X a 5+X a 7$, and Xa4/ qDTY2.2 showed less disease development under drought stress. However, the genotypes having $\mathrm{Xa4}, \mathrm{Xa4} / \mathrm{qDTY} 2.2+\mathrm{qDTY} 4.1$ were less effective to combined stresses. Severe drought stress reduces the bacterial multiplication due to higher leaf water loss. The rice genotype with $\mathrm{Xa} 7$ showed reduced bacterial multiplication under severe drought stress and was dependent on the tissue water status. Under severe drought stress, the leaf water loss is more which influences bacterial multiplication (Freeman and Beattie, 2009).

Single $X a$ gene is not sufficient to provide resistance. The rice genotype carrying single $\mathrm{Xa} 4$ gene showed increased $\mathrm{BB}$ severity under drought stress. The compromised resistance response was also observed in rice genotype having Xa4 gene under high temperature (Webb et al., 2010) and drought stress (Dossa et al., 2016). Similar reports were found in the combined stress of high temperature and $\mathrm{BB}$, drought stress and $\mathrm{BB}$ at the seedling stage. From this context, the QTLs associated with drought tolerance with multiple $\mathrm{Xa}$ genes at the seedling level may improve tolerance for combined stress. From this context, introgression of $\mathrm{Xa}$ genes with drought QTLs signifies that the drought-tolerant genotypes with specific QTLs could be beneficial for BB disease development. The drought tolerant genotypes that can maintain water loss by regulating stomata or by deep roots with specific $\mathrm{Xa}$ genes could contribute to $\mathrm{BB}$ tolerance and improve combined stress tolerance. Higher stomata and root hydraulic conductivity under drought showed inhibition of $\mathrm{BB}$ in rice genotypes having three different $\mathrm{Xa}$ genes (Yu et al., 2008, 2013; Henry et al., 2015). Studies demonstrated that, when two major $R$ genes (Xa4 and $\mathrm{Xa7}$ ) are present in a genotype, combined stress tolerance is enhanced. In a recent study to improve the multiple stress tolerance, four BB resistance genes ( $\mathrm{Xa} 4$, $x a 5, x a 13, X a 21)$ were pyramided with submergence (Sub1), salinity (Saltol), blast (Pi2, Pi9) and gall midge (Gm1, Gm4) improved Tapaswini an elite rice cultivar successfully that showed multiple stress tolerance (Das et al., 2018). The enhanced rice resistance to combined stress can be achieved by introgression of multiple drought QTLs and multiple $\mathrm{R}$ genes in a single elite genotype.

\section{GENETIC MANIPULATION FOR COMBINED STRESS TOLERANCE}

Several genes have been identified and functionally characterized for their role in specific pathways and stress responses. However, most of these studies were limited to the single type of stresses and this could be considered as a major limitation in transgenic research aimed for product development, as the plants were not evaluated under combined stress conditions that occur in the natural environmental conditions. Here, we list a few genes that are tested for multiple individual stresses that showed differential roles (Supplementary Table 1). However, none of these genes were tested for combined stress response, and hence the data presented here is only a speculation that these genes may provide tolerance.

Overexpression of MoHrip1 and MoHrip2 from M. oryzae in rice enhanced the resistance to bacterial disease caused by $X o o$ and drought stress. In transgenic plants, higher expression of two JA/ethylene biosynthesis-related genes OsLOX2 and OsAOS2 and SA signal-related genes OsEDS1, OsPAL1, $O s N H 1, O s P R-1 a$, and OsPR-10a was observed in response to bacterial pathogen and abiotic stress responsive genes OsbZIP23, OsZEP1, OsNCED2, and OsNCED3 were highly upregulated under drought conditions (Wang et al., 2017). A few TFs from NAC, WRKY, bHLH, AP2, and bZIP family have been shown to be induced upon both drought and bacterial stresses (Nakashima et al., 2007; Xiao et al., 2013; Jisha et al., 2015). The WRKY45-2 TF showed broad-spectrum disease resistance to $M$. oryzae, bacterial pathogens Xoo and Xanthomonas oryzae pv. oryzicola. However, this TF had been shown to act as a negative regulator of salt, cold, and drought stresses in rice (Tao et al., 2009, 2011). Similarly, overexpression of WRKY13 enhanced rice resistance to Xoo and M. oryzae and reduced resistance to cold and salt stresses by influencing the transcription of more than 500 genes (Qiu et al., 2007, 2008). Transcriptional repressor WRKY13 suppresses the expression of two important genes SNAC1 and WRKY45-1 by binding to sequence-specific W-like-type cis-elements on the promoters of these genes under abiotic and biotic stress. The autoregulation of WRKY13 is associated with balancing its function when the rice plants experience different stress environments (Xiao et al., 2013). Ectopic expression of OsWRKY11 resulted in upregulation of defense-associated genes and drought-responsive genes that improve stress tolerance. OsWRKY11 play positive regulator function in plant defense to drought and Xoo (Lee et al., 2018). Overexpression and suppression of a few specific genes resulted in resistance to combined biotic and abiotic stresses (Zhang et al., 2016). These studies demonstrate that the transcriptional regulators play a crucial role in improving multiple stress tolerance in rice. However, their response to combined stress needs to be assessed to gain more insight into their role in enhancing adaptation to natural environmental stresses. The genes that showed tolerance to both drought and Xoo could be attractive targets for genetic manipulation of rice for combined stress.

\section{CONCLUSION AND PERSPECTIVE}

1. The plant responses under combined drought and bacterial infection need further understanding and studies using simultaneous stress imposition are much needed. 
2. The existing transcriptome studies suggest combined stress responses are complex and sophisticated and hence detailed understanding of unique and shared signaling mechanisms is important.

3. Prospecting the candidate genes and functional validation using diverse approaches may lead to developing durable, resistant rice for combined bacterial and drought stress.

4. Understanding the regulatory networks involved in combined stress responses may provide an option to manipulate the signaling mechanisms which serve as a key for adaptation by using novel approaches such as genome editing tools.

5. Ribosomal protein-encoding genes seem to be attractive candidates for gene manipulation. However, the functional relevance in combined stress needs to be explored.

6. Combining drought QTLs and $X a$ genes could be a better strategy due to their success in the drought-prone areas. However, there is a need to identify QTLs at different stages of crop growth and develop introgressed lines, which may provide an option to improve rice for combined stress tolerance.

7. Pyramiding multiple genes/QTLs associated with multiple stresses in the elite background may provide durable resistance to combined stress.

8. Transgenics using candidate genes, which provide combined stress tolerance, are the best option because of their precise molecular mechanisms. However, more concerted efforts are needed to explore the candidate genes.

\section{REFERENCES}

Achard, P., Gong, F., Cheminant, S., Alioua, M., Hedden, P., and Genschik, P. (2008). The cold-inducible CBF1 factor-dependent signaling pathway modulates the accumulation of the growth-repressing DELLA proteins via its effect on gibberellin metabolism. Plant Cell 20, 2117-2129. doi: 10.1105/tpc.108.058941

Aghamolki, M. T. K., Yusop, M. K., Oad, F. C., Zakikhani, H., Jaafar, H. Z., Kharidah, S., et al. (2014). Heat stress effects on yield parameters of selected rice cultivars at reproductive growth stages. J. Food Agric. Environ. 12, 741-746.

Albrecht, C., Boutrot, F., Segonzac, C., Schwessinger, B., Gimenez-Ibanez, S., and Chinchilla, D. (2012). Brassinosteroids inhibit pathogen-associated molecular pattern-triggered immune signaling independent of the receptor kinase BAK1. Proc. Natl. Acad. Sci. U.S.A. 109, 303-308. doi: 10.1073/pnas.1109921108

Apel, K., and Hirt, H. (2004). Reactive oxygen species: metabolism, oxidative stress, and signal transduction. Annu. Rev. Plant Biol. 55, 373-399. doi: 10.1146/ annurev.arplant.55.031903.141701

Asano, T., Hayashi, N., Kobayashi, M., Aoki, N., Miyao, A., Mitsuhara, I., et al. (2012). A rice calcium-dependent protein kinase OsCPK12 oppositely modulates salt-stress tolerance and blast disease resistance. Plant J. 69, 26-36. doi: 10.1111/j.1365-313X.2011.04766.x

Asselbergh, B., De-Vleesschauwer, D., and Hofte, M. (2008). Global switches and fine-tuning-ABA modulates plant pathogen defense. Mol. Plant Microbe Interact. 21, 709-719. doi: 10.1094/MPMI-21-6-0709

Atkinson, N. J., Lilley, C. J., and Urwin, P. E. (2013). Identification of genes involved in the response of Arabidopsis to simultaneous biotic and abiotic stresses. Plant Physiol. 162, 2028-2041. doi: 10.1104/pp.113. 222372

Babitha, K. C., Vemanna, R. S., Karaba, N. N., Sheshshayee, M. S., and Udayakumar, M. (2015a). EcbZIP60, a basic leucine zipper transcription factor from Eleusine coracana $L$. improves abiotic stress tolerance in tobacco by activating unfolded protein response pathway. Mol Breed. 35:181. doi: 10.1007/ s11032-015-0374-6
9. The alternate strategies like discovery of novel small molecules or dsRNA-mediated approaches can be employed to improve combined stress tolerance.

\section{AUTHOR CONTRIBUTIONS}

$\mathrm{RV}$ conceived the concept and wrote a review. RV, RB, and PB drafted the manuscript. MK edited the pathogen-related and SS edited the drought-related aspects in manuscript. MS-K, UM, and RV edited and finalized the manuscript.

\section{FUNDING}

The projects at RV lab are supported by SERB Ramanujan Fellowship (Grant No. SB/S2/RJN-046/2016) and DBTInnovative Young Biotechnologist Award (Grant No. BT/010/IYBA/2016/09). The project at UM lab was supported by SERB-EMR (Grant No. EMR/2016/002078).

\section{SUPPLEMENTARY MATERIAL}

The Supplementary Material for this article can be found online at: https://www.frontiersin.org/articles/10.3389/fpls.2019.00193/ full\#supplementary-material

Babitha, K. C., Vemanna, R. S., Nataraja, K. N., and Udayakumar, M. (2015b). Overexpression of EcbHLH57 transcription factor from Eleusine coracana L. in tobacco confers tolerance to salt, oxidation and drought stress. PLoS One 10:e0137098. doi: 10.1371/journal.pone.0137098

Babitha, K. C., Vemanna, R. S., Pruthvi, V., Mahesh, P., Nataraja, K. N., and Udayakumar, M. (2013). Co-expression of AtbHLH17 and AtWRKY28 confers resistance to abiotic stress in Arabidopsis. Transgenic Res. 22, 327-341. doi: $10.1007 / \mathrm{s} 11248-012-9645-8$

Bahuguna, R. N., Gupta, P., Bagri, J., Singh, D., Azri Kusuma, D., Tao, L., et al. (2018). Forward and reverse genetics approaches for combined stress tolerance in rice. Ind. J. Plant Physiol. 23, 630-646. doi: 10.1007/s40502-018-0418-0

Bailey, T. L., Boden, M., Buske, F. A., Frith, M., Grant, C. E., Clementi, L., et al. (2009). Meme suite: tools for motif discovery and searching. Nucleic Acids Res. 37, W202-W208. doi: 10.1093/nar/gkp335

Belkhadir, Y., Jaillais, Y., Epple, P., Balsemao-Pires, E., Dangl, J. L., and Chory, J. (2012). Brassinosteroids modulate the efficiency of plant immune responses to microbe-associated molecular patterns. Proc. Natl. Acad. Sci. U.S.A. 109, 297-302. doi: 10.1073/pnas.1112840108

Cheong, Y. H., Chang, H. S., Gupta, R., Wang, X., Zhu, T., and Luan, S. (2002). Transcriptional profiling reveals novel interactions between wounding, pathogen, abiotic stress, and hormonal responses in Arabidopsis. Plant Physiol. 129, 661-677. doi: 10.1104/pp.002857

Cho, Y. H., Hong, J. W., Kim, E. C., and Yoo, S. D. (2012). Regulatory functions of SnRK1 in stress-responsive gene expression and in plant growth and development. Plant Physiol. 158, 1955-1964. doi: 10.1104/pp.111.189829

Choudhary, A., Pandey, P., and Senthil-Kumar, M. (2016). "Tailored responses to simultaneous drought stress and pathogen infection in plants," in Drought Stress Tolerance in Plants Vol. 1, eds M. A. Hossain, S. H. Wani, S. Bhattacharjee, D. J. Burritt, and L.-S. P. Tran (Berlin: Springer International Publishing), 427-438.

Das, G., Rao, G., Varier, M., Prakash, A., and Prasad, D. (2018). Improved Tapaswini having four BB resistance genes pyramided with six genes/QTLs, resistance/tolerance to biotic and abiotic stresses in rice. Sci. Rep. 8:2413. doi: 10.1038/s41598-018-20495-x 
Delteil, A., Blein, M., Faivre-Rampant, O., Guellim, A., Estevan, J., Hirsch, J., et al. (2012). Building a mutant resource for the study of disease resistance in rice reveals the pivotal role of several genes involved in defence. Mol. Plant Pathol. 13, 72-82. doi: 10.1111/j.1364-3703.2011.00731.x

Deng, H., Liu, H., Li, X., Xiao, J., and Wang, S. (2012). A CCCH-type zinc finger nucleic acid binding protein quantitatively confers resistance against rice bacterial blight disease. Plant Physiol. 158, 876-889. doi: 10.1104/pp.111.191379

Divi, U. K., Rahman, T., and Krishna, P. (2010). Brassinosteroid-mediated stress tolerance in Arabidopsis shows interactions with abscisic acid, ethylene and salicylic acid pathways. BMC Plant Biol. 10:151. doi: 10.1186/1471-2229-10-151

Dixit, S., Singh, A., and Kumar, A. (2014). Rice breeding for high grain yield under drought: a strategic solution to a complex problem. Int. J. Agron. 2014, 1-15. doi: 10.1155/2014/863683

Dossa, G. S., Torres, R., Henry, A., Oliva, R., Maiss, E., Cruz, C. V., et al. (2016). Rice response to simultaneous bacterial blight and drought stress during compatible and incompatible interactions. Eur. J. Plant Pathol. 147, 115-127. doi: 10.1007/ s10658-016-0985-8

Fatima, U., and Senthil-Kumar, M. (2017). "Tissue water status and bacterial pathogen infection: how they are correlated?", in Plant Tolerance to Individual and Concurrent Stresses, ed. M. Senthil-Kumar (New Delhi: Springer).

Freeman, B. C., and Beattie, G. A. (2009). Bacterial growth restriction during host resistance to Pseudomonas syringae is associated with leaf water loss and localized cessation of vascular activity in Arabidopsis thaliana. Mol. Plant Microbe Interact. 22, 857-867. doi: 10.1094/MPMI-22-7-0857

Fujiwara, T., Maisonneuve, S., Isshiki, M., Mizutani, M., Chen, L., Wong, H. L., et al. (2010). Sekiguchi lesion gene encodes a cytochrome P450 monooxygenase that catalyzes conversion of tryptamine to serotonin in rice. J. Biol. Chem. 285, 11308-11313. doi: 10.1074/jbc.M109.091371

Ghadirnezhad, R., and Fallah, A. (2014). Temperature effect on yield and yield components of different rice cultivars in flowering stage. Int. J. Agron. 2014:4. doi: 10.1155/2014/846707

Grimmer, M. K., John Foulkes, M., and Paveley, N. D. (2012). Foliar pathogenesis and plant water relations: a review. JXB 63, 4321-4331. doi: 10.1093/jxb/ers143

Hand, S. C., Menze, M. A., Toner, M., Boswell, L., and Moore, D. (2011). LEA proteins during water stress: not just for plants anymore. Annu. Rev. Physiol. 73, 115-134. doi: 10.1146/annurev-physiol-012110-142203

Hashimoto, M., Kisseleva, L., Sawa, S., Furukawa, T., Komatsu, S., and Koshiba, T. (2004). A novel rice PR10 protein, RSOsPR10, specifically induced in roots by biotic and abiotic stresses, possibly via the jasmonic acid signaling pathway. Plant Cell Physiol. 45, 550-559. doi: 10.1093/pcp/pch063

He, Z. H., He, D., and Kohorn, B. D. (1998). Requirement for the induced expression of a cell wall associated receptor kinase for survival during the pathogen response. Plant J. 14, 55-63. doi: 10.1046/j.1365-313X.1998.00 092.x

Henry, A., Mallikarjuna, S. B. P., Dixit, S., Torres, R. D., Batoto, T. C., Manalili, M., et al. (2015). Physiological mechanisms contributing to the QTL-combination effects on improved performance of IR64 rice NILs under drought. J. Exp. Bot. 66, 1787-1799. doi: 10.1093/jxb/eru506

Hu, H. H., Dai, M. Q., Yao, J. L., Xiao, B. Z., Li, X. H., Zhang, Q. F., et al. (2006). Overexpressing a NAM, ATAF, and CUC (NAC) transcription factor enhances drought resistance and salt tolerance in rice. Proc. Natl. Acad. Sci. U.S.A. 103, 12987-12992. doi: 10.1073/pnas.0604882103

$\mathrm{Hu}$, W., Hu, G., and Han, B. (2009). Genome-wide survey and expression profiling of heat shock proteins and heat shock factors revealed overlapped and stress specific response under abiotic stresses in rice. Plant Sci. 176, 583-590. doi: 10.1016/j.plantsci.2009.01.016

Huang, T.-L., Huang, L.-Y., Fu, S.-F., Trinh, N.-N., and Huang, H.-J. (2014). Genomic profiling of rice roots with short- and long-term chromium stress. Plant Mol. Biol. 86, 157-170. doi: 10.1007/s11103-014-0219-4

Jain, M., Nijhawan, A., Arora, R., Agarwal, P., Ray, S., Sharma, P., et al. (2007). F-box proteins in rice. Genome-wide analysis, classification, temporal and spatial gene expression during panicle and seed development, and regulation by light and abiotic stress. Plant Physiol. 143, 1467-1483. doi: 10.1104/pp.106. 091900

Jeong, J. S., Kim, Y. S., Baek, K. H., Jung, H., Ha, S. H., Do Choi, Y., et al. (2010). Root-specific expression of OsNAC10 improves drought tolerance and grain yield in rice under field drought conditions. Plant Physiol. 153, 185-197. doi: $10.1104 /$ pp. 110.154773
Jisha, V., Dampanaboina, L., Vadassery, J., Mithofer, A., Kappara, S., and Ramanan, R. (2015). Overexpression of an AP2/ERF type transcription factor OsEREBP1 confers biotic and abiotic stress tolerance in rice. PLoS One 10:e0127831. doi: 10.1371/journal.pone.0127831

Kaundal, A., Vemanna, R. S., Oh, S., Lee, S., Pant, B., Lee, H. K., et al. (2017). General control nonrepressible4 degrades 14-3-3 and the RIN4 complex to regulate stomatal aperture with implications on nonhost disease resistance and drought tolerance. Plant Cell 29, 2233-2248. doi: 10.1105/tpc.17.00070

Khan, M. A., Naeem, M., and Iqbal, M. (2014). Breeding approaches for bacterial leaf blight resistance in rice (Oryza sativa L.), current status and future directions. Eur. J. Plant Pathol. 139, 27-37. doi: 10.1007/s10658-014-0377-x

Kim, D. Y., Kwon, S. I., Choi, C., Lee, H., Ahn, I., Park, S. R., et al. (2013). Expression analysis of rice VQ genes in response to biotic and abiotic stresses. Gene 529, 208-214. doi: 10.1016/j.gene.2013.08.023

Kohorn, B. D., and Kohorn, S. L. (2012). The cell wall-associated kinases, WAKs, as pectin receptors. Front. Plant Sci. 3:88. doi: 10.3389/fpls.2012.00088

Ku, Y. S., Sintaha, M., Cheung, M. Y., and Lam, H. M. (2018). Plant hormone signaling crosstalks between biotic and abiotic stress responses. Int. J. Mol. Sci. 19:3206. doi: 10.3390/ijms19103206

Lampayan, R. M., Bouman, B. A. M., De Dios, J. L., Lactaoen, A. T., Espiritu, A. J., Norte, T. M., et al. (2004). Adoption of water saving technologies in rice production in the philippines. Ext. Bull. 548:15.

Lee, H., Cha, J., Choi, C., Choi, N., Ji, H. S., Park, S. R., et al. (2018). Rice WRKY11 plays a role in pathogen defense and drought tolerance. Rice 11:5. doi: 10.1186/s12284-018-0199-0

Li, L., Kim, P., Yu, L., Cai, G., Chen, S., Alfano, J. R., et al. (2016). Activationdependent destruction of a co-receptor by a pseudomonas syringae effector dampens plant immunity. Cell Host Microbe 20, 504-514. doi: 10.1016/j.chom. 2016.09.007

Liu, X., Bai, X., Wang, X., and Chu, C. (2007). OsWRKY71, a rice transcription factor, is involved in rice defense response. J. Plant Physiol. 164, 969-979. doi: 10.1016/j.jplph.2006.07.006

Mao, C., Ding, W., Wu, Y., Yu, J., He, X., Shou, H., et al. (2007). Overexpression of a NAC domain protein promotes shoot branching in rice. New Phytol. 176, 288-298. doi: 10.1111/j.1469-8137.2007.02177.x

Marcel, S., Sawers, R., Oakeley, E., Angliker, H., and Paszkowski, U. (2010). Tissueadapted invasion strategies of the rice blast fungus Magnaporthe oryzae. Plant Cell 22, 3177-3187. doi: 10.1105/tpc.110.078048

Moin, M., Bakshi, A., Saha, A., Dutta, M., Madhav, S. M., and Kirti, P. B. (2016). Rice ribosomal protein large subunit genes and their spatio-temporal and stress regulation. Front. Plant Sci. 7:1284. doi: 10.3389/fpls.2016.01284

Nagaraj, S., Senthil-Kumar, M., Vemanna, S. R., Wang, K., and Mysore, K. S. (2016). Plant ribosomal proteins, RPL12 and RPL19, play a role in non host disease resistance against bacterial pathogens. Front. Plant Sci. 6:1192. doi: 10.3389/fpls.2015.01192

Nakashima, K., Tran, L. S., Van-Nguyen, D., Fujita, M., Maruyama, K., Todaka, D., et al. (2007). Functional analysis of a NAC-type transcription factor OsNAC6 involved in abiotic and biotic stress-responsive gene expression in rice. Plant J. 51, 617-630. doi: 10.1111/j.1365-313X.2007.03168.x

Narsai, R., Wang, C., Chen, J., Wu, J., Shou, H., and Whelan, J. (2013). Antagonistic, overlapping and distinct responses to biotic stress in rice (Oryza sativa) and interactions with abiotic stress. BMC Genomics 14:93. doi: 10.1186/ 1471-2164-14-93

Narusaka, Y., Narusaka, M., Seki, M., Umezawa, T., Ishida, J., Nakajima, M., et al. (2004). Crosstalk in the responses to abiotic and biotic stresses in Arabidopsis: analysis of gene expression in cytochrome P450 gene superfamily by cDNA microarray. Plant Mol. Biol. 55, 327-342. doi: 10.1007/s11103-0040685-1

Navarro, L., Bari, R., Achard, P., Lison, P., Nemri, A., Harberd, N. P., et al. (2008). DELLAs control plant immune responses by modulating the balance of jasmonic acid and salicylic acid signaling. Curr. Biol. 18, 650-655. doi: 10.1016/j.cub.2008.03.060

Nolan, T., Chen, J., and Yin, Y. (2017). Cross- talk of Brassinosteroid signaling in controlling growth and stress responses. Biochem. J. 27 474, 2641-2661. doi: 10.1042/BCJ20160633

Ogawa, T. (1993). Methods and strategy for monitoring race distribution and identification of resistance genes to bacterial leaf blight (Xanthomonas campestris pv. oryzae) in rice. JARQ 27, 1-80. 
Pandey, P., Irulappan, V., Bagavathiannan, M. V., and Kumar, M. S. (2017). Impact of combined abiotic and biotic stresses on plant growth and avenues for crop improvement by exploiting physio-morphological traits. Front. Plant Sci. 8:537. doi: 10.3389 /fpls.2017.00537

Pandey, P., Ramegowda, V., and Senthil-Kumar, M. (2015a). Shared and unique responses of plants to multiple individual stresses and stress combinations: physiological and molecular mechanisms. Front. Plant Sci. 6:723. doi: 10.3389/ fpls.2015.00723

Pandey, P., Sinha, R., Mysore, K. S., and Senthil-Kumar, M. (2015b). "Impact of concurrent drought stress and pathogen infection on plants," in Combined Stresses in Plants, ed. R. Mahalingam (Cham: Springer International Publishing), 203-222.

Pantuwan, G., Fukai, S., Cooper, M., Rajatasereekul, S., and O’Toole, J. C. (2000). "Yield responses of rice (Oryza sativa L.) Genotypes to water deficit in rainfed lowlands," in Proceedings of an International Workshop on Field Screening for Drought Tolerance in Rice, (Patancheru: ICRISAT).

Park, C. J., Han, S. W., Chen, X., and Ronald, P. C. (2010). Elucidation of XA21mediated innate immunity. Cell Microbiol. 12, 1017-1025. doi: 10.1111/j.14625822.2010.01489.x

Pradhan, S. K., Nayak, D. K., Mohanty, S., Behera, L., Barik, S. R., Pandit, E., et al. (2015). Pyramiding of three bacterial blight resistance genes for broad-spectrum resistance in deepwater rice variety, Jalmagna. Rice 8:19. doi: 10.1186/s12284015-0051-8

Prasch, C. M., and Sonnewald, U. (2013). Simultaneous application of heat, drought, and virus to Arabidopsis plants reveals significant shifts in signaling networks. Plant Physiol. 162, 1849-1866. doi: 10.1104/pp.113.221044

Prince, S. J., Beena, R., Gomez, S. M., Senthivel, S., and Chandra Babu, R. (2015). Mapping consistent rice (Oryza sativa L.) Yield QTLs under drought stress in target rainfed environments. Rice 8:53. doi: 10.1186/s12284-015-0053-6

Qiu, D., Xiao, J., Ding, X., Xiong, M., Cai, M., Cao, Y., et al. (2007). OsWRKY13 mediates rice disease resistance by regulating defense related genes in salicylateand jasmonate-dependent signaling. Mol. Plant Microbe Interact. 20, 492-499. doi: 10.1094/MPMI-20-5-0492

Qiu, D., Xiao, J., Xie, W., Liu, H., Li, X., Xiong, L., et al. (2008). Rice gene network inferred from expression profiling of plants overexpressing OsWRKY13, a positive regulator of disease resistance. Mol. Plant 1, 538-551. doi: 10.1093/mp/ ssn012

Qiu, Y., and Yu, D. (2009). Over-expression of the stress-induced OsWRKY45 enhance disease resistance and drought tolerance in Arabidopsis. Environ. Exp. Bot. 65, 35-47. doi: 10.1016/j.envexpbot.2008.07.002

Ramegowda, V., and Senthil-kumar, M. (2015). The interactive effects of simultaneous biotic and abiotic stresses on plants: mechanistic understanding from drought and pathogen combination. J. Plant Physiol. 176, 47-54. doi: $10.1016 /$ j.jplph.2014.11.008

Ranty, B., Aldon, D., Cotelle, V., Galaud, J. P., Thuleau, P., and Mazars, C. (2016). Calcium sensors as key hubs in plant responses to biotic and abiotic stresses. Front. Plant Sci. 7:327. doi: 10.3389/fpls.2016.00327

Ribot, C., Hirsch, J., Balzergue, S., Tharreau, D., Notteghem, J. L., Lebrun, M. H., et al. (2008). Susceptibility of rice to the blast fungus, Magnaporthe grisea. J. Plant Physiol. 165, 114-124. doi: 10.1016/j.jplph.2007. 06.013

Rodrigo, G., Carrera, J., Ruiz-Ferrer, V., del-Toro, F. J., Llave, C., Voinnet, O., et al. (2012). A Meta-Analysis reveals the commonalities and differences in Arabidopsis thaliana response to different viral pathogens. PLoS One 7:e40526. doi: 10.1371/journal.pone.0040526

Saha, A., Das, S., Moin, M., Dutta, M., Bakshi, A., Madhav, M. S., et al. (2017). Genome wide identification and comprehensive expression profiling of ribosomal protein smallsubunit (RPS) genes and their comparative analysis with the large subunit (RPL) genes in rice. Front. Plant Sci. 8:1553. doi: 10.3389/ fpls.2017.01553

Savary, S., Ficke, A., Aubertot, J. N., and Hollier, C. (2012). Crop losses due to diseases and their implications for global food production losses and food security. Food Sec. 4, 519-537. doi: 10.1007/s12571-0120200-5

Schenk, P. M., Kazan, K., Wilson, I., Anderson, J. P., Richmond, T., Somerville, S. C., et al. (2000). Coordinated plant defense responses in Arabidopsis revealed by microarray analysis. Proc. Natl. Acad. Sci. U.S.A. 97, 11655-11660. doi: 10.1073/pnas.97.21.11655
Seki, M., Narusaka, M., Ishida, J., Nanjo, T., Fujita, M., Oono, Y., et al. (2002). Monitoring the expression profiles of 7000 Arabidopsis genes under drought, cold and high-salinity stresses using a full-length cDNA microarray. Plant J. 31, 279-292. doi: 10.1046/j.1365-313X.2002.01359.x

Seo, Y. S., Chern, M., Bartley, L. E., Han, M., Jung, K. H., Lee, I., et al. (2011). Towards establishment of a rice stress response interactome. PLoS Genet. 7:e1002020. doi: 10.1371/journal.pgen. 1002020

Shaik, R., and Ramakrishna, W. (2013). Genes and coexpression modules common to drought and bacterial stress responses in Arabidopsis and rice. PLoS One 8:e77261. doi: 10.1371/journal.pone.0077261

Shaik, R., and Ramakrishna, W. (2014). Machine learning approaches distinguish multiple stress conditions using stress-responsive genes and identify candidate genes for broad resistance in rice. Plant Physiol. 164, 481-495. doi: 10.1104/pp. 113.225862

Sharma, R., Vleesschauwer, D. D., Sharma, M. K., and Ronald, P. C. (2013). Recent advances in dissecting stress-regulatory crosstalk in rice. Mol. Plant 6, 250-260. doi: $10.1093 / \mathrm{mp} / \mathrm{sss} 147$

Singh, C. M., Binod, K., Suhel, M., and Kunj, C. (2012). Effect of drought stress in rice: a review on morphological and physiological characteristics. Trends Biosci. $5,261-265$.

Suzuki, N., Rivero, R. M., Shulaev, V., Blumwald, E., and Mittler, R. (2014). Abiotic and biotic stress combinations. New Phytol. 203, 32-43. doi: 10.1111/nph. 12797

Swarbrick, P. J., Huang, K., Liu, G., Slate, J., Press, M. C., and Scholes, J. D. (2008). Global patterns of gene expression in rice cultivars undergoing a susceptible or resistant interaction with the parasitic plant Striga hermonthica. New Phytol. 179, 515-529. doi: 10.1111/j.1469-8137.2008.02484.x

Takasaki, H., Maruyama, K., Kidokoro, S., Ito, Y., Fujita, Y., Shinozaki, K., et al. (2010). The abiotic stress-responsive NAC-type transcription factor OsNAC5 regulates stress-inducible genes and stress tolerance in rice. Mol. Genet. Genomics 284, 173-183. doi: 10.1007/s00438-010-0557-0

Tao, Z., Kou, Y., Liu, H., Li, X., Xiao, J., and Wang, S. (2011). OsWRKY45 alleles play different roles in abscisic acid signalling and salt stress tolerance but similar roles in drought and cold tolerance in rice. J. Exp. Bot. 62, 4863-4874. doi: 10.1093/jxb/err144

Tao, Z., Liu, H., Qiu, D., Zhou, Y., Li, X., Xu, C., et al. (2009). A pair of allelic WRKY genes play opposite roles in rice-bacteria interactions. Plant Physiol. 151, 936-948. doi: 10.1104/pp.109.145623

Tippmann, H. F., Schluter, U., and Collinge, D. B. (2006). Common Themes in Biotic and Abiotic Stress Signalling in Plants. Middlesex: Global Science Books.

Ton, J., Flors, V., and Mauch-Mani, B. (2009). The multifaceted role of ABA in disease resistance. Trends Plant Sci. 14, 310-317. doi: 10.1016/j.tplants.2009.03. 006

Torres, M. A., and Dangl, J. L. (2005). Functions of the respiratory burst oxidase in biotic interactions, abiotic stress and development. Curr. Opin. Plant Biol. 8, 397-403. doi: 10.1016/j.pbi.2005.05.014

Vemanna, R. S., Paramanantham, A., Ramegowda, V., Mohan-Raju, B., Udayakumar, M., and Senthil-Kumar, M. (2016). Transcriptome analysis of sunflower genotypes with contrasting oxidative stress tolerance reveals individual and combined biotic and abiotic stress tolerance mechanisms. PLoS One 11:e0157522. doi: 10.1371/journal.pone.0157522

Verdier, V., Vera Cruz, C., and Leach, J. E. (2012). Controlling rice bacterial blight in Africa: needs and prospects. J. Biotechnol. 159, 320-328. doi: 10.1016/ j.jbiotec.2011.09.020

Wang, Z., Han, Q., Zi, Q., Lv, S., Qiu, D., and Zeng, H. (2017). Enhanced disease resistance and drought tolerance in transgenic rice plants overexpressing protein elicitors from Magnaporthe oryzae. PLoS One 12:e0175734. doi: 10.1371/journal.pone.0175734

Webb, K. M., Ona, I., Bai, J., Garrett, K. A., Mew, T., Vera-Cruz, C. M., et al. (2010). A benefit of high temperature: increased effectiveness of a rice bacterial blight disease resistance gene. New Phytol. 185, 568-576. doi: 10.1111/j.1469-8137. 2009.03076.x

Wright, C. A., and Beattie, G. A. (2004). Pseudomonas syringae pv. tomato cells encounter inhibitory levels of water stress during the hypersensitive response of Arabidopsis thaliana. Proc. Natl. Acad. Sci. U.S.A. 101, 3269-3274. doi: 10.1073/ pnas. 0400461101

Xiao, J., Cheng, H., Li, X., Xiao, J., Xu, C., and Wang, S. (2013). Rice WRKY13 regulates cross talk between abiotic and biotic stress signaling pathways by 
selective binding to different cis-elements. Plant Physiol. 163, 1868-1882. doi: 10.1104/pp.113.226019

Xiong, L. Z., and Yang, Y. N. (2003). Disease resistance and abiotic stress tolerance in rice are inversely modulated by an abscisic acid-inducible mitogen-activated protein kinase. Plant Cell 15, 745-759. doi: 10.1105/tpc. 008714

Yamada, K., Yamashita-Yamada, M., Hirase, T., Fujiwara, T., Tsuda, K., Hiruma, K., et al. (2015). Danger peptide receptor signaling in plants ensures basal immunity upon pathogen-induced depletion of BAK1. EMBO J. 35, 46-61. doi: $10.15252 / \mathrm{embj} .201591807$

Yamanouchi, U., Yano, M., Lin, H., Ashikari, M., and Yamada, K. (2002). A rice spotted leaf gene, Spl7, encodes a heat stress transcription factor protein. Proc. Natl. Acad. Sci. U.S.A. 99, 7530-7535. doi: 10.1073/pnas.11220 9199

Yang, D. L., Yang, Y., and He, Z. (2013). Roles of plant hormones and their interplay in rice immunity. Mol. Plant 6, 675-685. doi: 10.1093/mp/ sst056

Yao, J. L., Kops, O., Lu, P. J., and Lu, K. P. (2001). Functional conservation of phosphorylation specific prolyl isomerases in plants. J. Biol. Chem. 276, 13517-13523. doi: 10.1074/jbc.M007006200

Yu, H., Chen, X., Hong, Y. Y., Wang, Y., Xu, P., Ke, S. D., et al. (2008). Activated expression of an Arabidopsis HD-START protein confers drought tolerance with improved root system and reduced stomatal density. Plant Cell 20, 1134-1151. doi: 10.1105/tpc.108.058263

Yu, L., Xi, C., Zhen, W., Shimei, W., Yuping, W., Qisheng, Z., et al. (2013). Arabidopsis enhanced drought tolerancel/homeodomain glabrous11 confers drought tolerance in transgenic rice without yield penalty. Plant Physiol. 162, 1378-1391. doi: 10.1104/pp.113.217596
Zhang, F., Zhang, F., Huang, L., Cruz, C. V., Ali, J., Xu, J., et al. (2016). Overlap between signaling pathways responsive to Xanthomonas oryzae pv. oryzae infection and drought stress in rice introgression line revealed by RNA-Seq. J. Plant Growth Regul. 35, 345-356. doi: 10.1007/s00344-0159538-1

Zhang, F., Zhuoa, D. L., Zhang, F., Huang, L. Y., Wang, W. S., Xu, J. L., et al. (2014). Xa39, a novel dominant gene conferring broad-spectrum resistance to Xanthomonas oryzae pv. oryzae in rice. Plant Pathol. 64, 568-575. doi: 10.1111/ ppa. 12283

Zhang, H., and Sonnewald, U. (2017). Differences and commonalities of plant responses to single and combined stresses. Plant J. 90, 839-855. doi: 10.1111/ tpj.13557

Zhou, Y. L., Xu, M. R., Zhao, M. F., Xie, X. W., Zhu, L. H., Fu, B. Y., et al. (2010). Genome-wide gene responses in a transgenic rice line carrying the maize resistance gene Rxol to the rice bacterial streak pathogen, Xanthomonas oryzae pv. oryzicola. BMC Genomics 11:78. doi: 10.1186/1471-2164-11-78

Conflict of Interest Statement: The authors declare that the research was conducted in the absence of any commercial or financial relationships that could be construed as a potential conflict of interest.

Copyright $\odot 2019$ Vemanna, Bakade, Bharti, Kumar, Sreeman, Senthil-Kumar and Makarla. This is an open-access article distributed under the terms of the Creative Commons Attribution License (CC BY). The use, distribution or reproduction in other forums is permitted, provided the original author(s) and the copyright owner(s) are credited and that the original publication in this journal is cited, in accordance with accepted academic practice. No use, distribution or reproduction is permitted which does not comply with these terms. 